\title{
THE IMPACT OF DigITAL PlATFORMS AND SOCIAL MEDIA ON THE FREEDOM OF EXPRESSION AND PLURALISM
}

\begin{abstract}
MARCIN WiELEC, BARTŁOMIEJ ORĘZIAK, ALEŠ ROZEHNAL, DAVOR DERENČINOVIĆ, DUŠAN V. POPOVIĆ, GÁBOR HULKÓ, ANDRÁS KOLTAY, KRISTINA ČUfAR, SANJA SAVČIĆ
\end{abstract}

\section{Introduction}

This chapter summarizes the considerations made to date in the previous chapters of this scientific monograph.

\section{The impact of digital platforms and social media on the freedom of expression and pluralism}

The chapter by Marcin Wielec investigates the impact of digital platforms and social media on freedom of expression and pluralism. The author attempts to determine the scale of the influence, benefits, and dangers of the existing operating structure of digital platforms and social media.

Marcin Wielec, Bartłomiej Oręziak, Aleš Rozehnal, Davor Derenčinović, Dušan V. Popović, Gábor Hulkó, András Koltay, Kristina Čufar, Sanja Savčić (2021) The Impact of Digital Platforms and Social Media on the Freedom of Expression and Pluralism. In: Marcin Wielec (ed.) The Impact of Digital Platforms and Social Media on the Freedom of Expression and Pluralism, pp. 311-322. Budapest-Miskolc, Ferenc Mádl Institute of Comparative Law-Central European Academic Publishing. 
The author discusses the most important regulations in Poland regarding freedom of expression, censorship, and fake news. These include the Constitution of the Republic of Poland of 1997, the Act of September 15, 2000, Code of Commercial Companies, the Polish Criminal Code, the Polish Civil Code, the Act of December 18, 1998, on the Institute of National Remembrance - Commission for the Prosecution of Crimes against the Polish Nation. The author also explores a draft act on the protection of the freedom of social network users, which was sent to the chancellery of the Prime Minister on January 22, 2021, with a request for entry in the list of legislative work of the Council of Ministers.

The author reviewed national legislation for the admission of digital platforms and social media to individual country markets (organizational form, country branch office, legal obligations, operating restrictions, etc.) and analyzed the legal liability of the creation, dissemination, and use of fake news from the perspective of administrative, criminal, and civil laws.

\section{Censorship on digital platforms and social media versus freedom of expression and pluralism in the Republic of Poland}

Bartłomiej Oręziak's chapter raises an important issue from the current social perspective in the Republic of Poland and considers freedom of expression and pluralism in opposition to the issue of censorship in digital platforms and social media. This chapter provides a scientific analysis of censorship on digital platforms and social media in relation to freedom of speech and pluralism from the perspective of the Republic of Poland. This analysis comprises three main research segments that constitute the basic axis through which the problem is considered.

According to the author, censorship should be divided into censorship permitted by law and censorship not regulated by law. The author considers it necessary to discuss censorship first, which remains lawful and concerns content posted on the Polish Internet, based on the European Union (EU) regulations regarding the principles of copyright on the Internet as defined in the latest case law of the Court of Justice of the EU. The author later refers to research issues concerning censorship in relation to digital platforms and social media in Poland.

This chapter recognizes the fundamental importance of the standard of freedom of expression and pluralism established in Poland, as well as the normative grounds for any restrictions in this regard. In addition, the author analyzes the compliance of the Polish legal system to the regulation of censorship with the standards of human rights protection. 


\section{The regulation of social media platforms in Hungary}

The chapter by András Koltay, devoted to the regulation of social media platforms in Hungary, presents an overview of various issues related to the functioning of social media platforms that have a significant impact on society. This chapter addresses legal regulations and case laws in the Hungarian legal system. The first part covers general issues related to the definition of censorship and its application, as well as various issues regarding the interpretation of censorship in relation to social media and its various manifestations. The second part focuses on the legal measures available to combat fake news and disinformation.

This chapter states that the legal relationship between social media platforms and their users (which is not affected by the constitutional doctrines of freedom of speech) is also regulated by law through an agreement concluded by and between the parties. The author draws attention to the issues of law enforcement in relation to social platforms. However, the author finds that it is not possible to enforce the principles and doctrines of freedom of speech in the online world with as much fervor as can be employed in offline spaces. With the advent of the Internet, the right to freedom of speech has entered a new phase of development with unforeseeable consequences.

The author asserts that government decision-makers and public policymakers need to adopt a systemic approach that considers the distinctive features of gatekeepers' activities, tracks their changes, provides an accurate definition of what is expected from gatekeepers and what they might expect from the law, and accurately establishes the duties and scope of liability of gatekeepers. The impact of gatekeepers on public communication and the strengthening of private regulations necessitate the use of new, creative, and innovative regulatory methods and institutions, the invention of new methods of establishing rules, and the degree of cooperation between public and private actors, which is unprecedented in this field.

As the author states, regarding the problem of fake news, the current doctrine of freedom of speech as applied in Europe does not exclude the prohibition of publication of falsehoods; hence, these cannot enjoy general constitutional protection. False statements of fact can, in certain cases, be restricted. However, the general prohibition of false statements is difficult to imagine. Simultaneously, this is a serious and massive problem for public communication and discussion of public affairs, especially on large online platforms. Any possible regulation is either contrary to the principles of freedom of speech or is likely to be ineffective. For the time being, states seem to accept their inability to regulate the public sphere without the platforms and deliberately hand over their former exclusive state function of setting the boundaries of freedom of speech to the platforms. 


\section{The impact of digital platforms and social media on the freedom of expression and pluralism in Serbia}

The chapter by Sanja Radovanović addresses the issue of freedom of speech in relation to Internet activities. The author points out that the Constitution Act of Serbia protects freedom of expression as a fundamental right but simultaneously constitutes a framework for its restriction. In that sense, freedom of expression could be limited by the rights and reputation of others to uphold the authority and objectivity of the court and protect the public health, democratic social morals, and national security of the Republic of Serbia. To fulfill both aims, the provisions of several laws prescribe certain content that could result in violation or jeopardizing others' rights. These were not numerus clausus cases. In that sense, if some content is not explicitly recognized as inappropriate, this does not mean that it is allowed. The court, deciding on an eventual dispute, determines whether expressed content is convenient to violate someone's right or which one of the confronted rights needs protection in a specific situation.

The provisions analyzed in the chapter on Serbian law concern the media under Serbian jurisdiction. Regarding media service providers out of the jurisdiction of Serbian law and authorities, and in particular social networks that are unregulated by state law, it appears impossible to control content distributed among users and to the public. The most common problem that emerges on a daily basis occurs when the Internet provider enables the posting of illegal content and sharing among users. The liability of Internet intermediaries-information society service providers in the law of the Republic of Serbia-is normally regulated by the Law on Electronic Commerce.

The chapter notes that traditional media in Serbia still take the lead in shaping public opinion and social trends. However, the increasingly frequent reactions of traditional media to events on social networks indicate the gradual influence of social networks and their inevitable inclusion in media flows. Nevertheless, social networks do not (at least directly) fall under Serbian law and jurisdiction.

The direct enforcement of domestic law on the Internet is possible only within the field in which the state has sovereignty, which is expressed through territorial and personal authority over certain segments of architecture and content. The only way for a state to fully implement its legal system on the Internet is to take full control of the physical and logical layers of the system.

The social harm incurred by spreading false news in Serbia has been recognized by the Criminal Code-concretely by the offense entitled Causing panic and disorder. Based on Serbian case law, the more frequently invoked claim against fake news creators seems to be for monetary damages. However, unlike the specific rules on damage compensation in cases in which harmful content is provided by journalists, on the same request against the media due to damages caused by fake news, the general rules of tort law are applicable. This is due to the law of 
public information and media, which stipulates the liability of the journalist and editor-in-chief for damages. Previous observations considered Serbian laws that could be applicable in the case of fake news when it caused relevant legal consequences. From a legal perspective, it would be considerably difficult to define who should be the arbiter of truth.

\section{Social media, freedom of expression, and the legal regulation of fake news in Croatia}

The chapter by Davor Derenčinović focuses on freedom of expression on social networks and its limitations. Special consideration is given to censorship on the Internet and the responsibility for disseminating fake news in cyberspace. Analyzing the advantages and disadvantages of the legal regulation of social networks, the current and prospective Croatian legal framework is presented and compared to the relevant legislation adopted recently in some European countries. Particular emphasis is given to the issue of service providers' responsibility for content generated by users, which was subject to deliberations of the European Court of Human Rights in several important cases. In summary, this paper aims to scrutinize and analyze regulations and procedures, identify their weak points, and offer proposals to improve dysfunctional legislation and ineffective implementation of Internet and social network policies.

According to some estimates, in 2019 , slightly more than $50 \%$ of people worldwide had access to the Internet, while in 2009, this number was significantly lower (less than 5\%). Over a year later, that number was estimated to be over five billion people, around $65 \%$ of the global population. According to some estimates, in 2017, there were about 2.86 billion social media users, with 3.6 billion in 2020 . It is estimated that by 2025 , about 4.41 billion people will have profiles on social networks.

This exponential growth of users has not been coupled with increased media literacy, knowledge about the risks of victimization on global networks, or public awareness of harmful content. Undoubtedly, this social context has created confusion and disorientation among people, most of whom use the Internet and social networks, making them more vulnerable to victimization, abuse, and manipulation both physically and in cyberspace.

Abuse in cyberspace is characterized by the phenomenon of discrimination between social media and networks. There are numerous examples of the use of speech that does not enjoy protection under Art. 10 of the European Convention for the Protection of Human Rights and Fundamental Freedoms. The jurisprudence of domestic courts and the European Court of Human rights confirm elements 
of a legitimate aim and proportionality principle in restricting the speech that, without any function in a democratic society, causes harm to others.

This chapter also focuses on preventing discrimination in cyberspace and other forms of expression that threaten European values, democracy, human rights, and the rule of law, such as disinformation campaigns aimed at disseminating fake news on social media and networks. In this context, the author focuses on the concept of responsibility of electronic media for user-generated content and prevention-based models aimed at raising public awareness about harmful Internet content and increasing media literacy.

\section{Legal aspects of content censorship on social networks in Slovenia}

The chapter by Kristina Čufar addresses the regulation of hate speech on Facebook and the problematic spread of misinformation and disinformation on social media. It approaches these issues by untangling the complex network of private and public regulation, paying special attention to Slovenian legislation, case law, and scholarship on the subject. The topics of hate speech and fake news are discussed, and Facebook is chosen as an example because it has the most users and the most diverse user structure of all social networks popular in Slovenia. Private censorship is a controversial topic. However, it must be acknowledged that social networks must engage in content moderation to provide a safe space for their users, remove illegal content, and appease the public, existing and potential users, states, partners, and advertisers. Therefore, the central question is not how to stop social networks from moderating content but how such practices are regulated and should be regulated in the future.

In the current era, Internet spaces are dominated by profit-driven enterprises, the algorithms of which sometimes contribute to the rise of incendiary speech and misinformation and disinformation. More speech does not necessarily mean better speech-hate speech, threats, and insults are often used to silence certain groups and may harden the pluralism of public debates. These trends are emerging in Slovenia, as social media allows anyone to express and circulate their ideas, and vulgar and offensive language often trumps nuanced discussions. People thus find themselves targeted and silenced by anonymous users, which contributes to the polarization of society and places freedom of expression up for grabs, available to the loudest and most aggressive speakers. The idea of democratic debate, conversely, presupposes a minimal level of civility and the use of arguments. As a young democracy, Slovenia has cultivated a permissive attitude toward freedom of expression, owing to the abuse of the prohibition of hostile propaganda in the former Socialist Federal Republic of Yugoslavia. Nevertheless, the Slovenian legal 
system restricts individuals' freedom of expression with the freedoms and rights of others to ensure open participation in democratic debate and prevent the abuse of this freedom. Case law involving problematic expressions on social networks reveals that social networks have certain particularities compared to other forums of expression.

The chapter situates the existing Slovenian regulations in the EU legal framework. It considers the regulative approaches of social media companies on Facebook as an example to demonstrate the complexity of private content moderation and its intersections with national and transnational regulation. This chapter presents Facebook's rules and procedures for content moderation and engages with the phenomenon of fake news and its perception, unpacked upon a classification of different types of misinformation and disinformation common in the Slovenian (social) media-sphere. As social media platforms host user-generated content and do not create or edit the content on their platforms, they are not considered to be media platforms under Slovenian legislation. As host service providers, they are excluded from the liability for the content they host if they are not aware of its illegality and must only remove it once the illegality of the content is officially established. While users cannot demand a reinstatement of a deleted post under Slovenian legislation, they may demand the legal removal of an illegal post.

The ability to create and disseminate misinformation and disinformation is not systematically regulated in Slovenia; however, such activities may result in legal accountability. While misinformation and disinformation on social media influence people's perceptions of reality, it is extremely difficult to efficiently regulate it. It is impossible to draw a fine line between necessary regulations and freedom of expression or between opinions and lies. Similarly, the fine line between censorship that stifles public debate and necessary content moderation is a political question that can never be conclusively answered. The regulation of expression on social networks and related dilemmas are not unique or limited to Slovenia and will remain to be governed by social networks, states, transnational entities, and other non-state actors. States lack the infrastructure to govern expressions on social networks effectively. Nevertheless, blindly trusting social network companies to discriminate adequately between legal and illegal expression is insufficient. Well-meaning obligations imposed on social networks to remove illegal content may result in the excessive removal of user-generated content; therefore, the cooperation and inclusion of a wide scope of actors are of utmost importance. More transparency, democratic oversight, and redress procedures are thus necessary. Furthermore, users should be adequately informed about social network companies' modus operandi (the algorithmic architecture of their platforms, use of data, advertising practices, options to opt out, rules and procedures for content moderation available in local language). They should have a say in the rules and procedures and be recompensed for their data and time. The EU has an important role to play in this process and is attempting to address the described issues and 
curb the power of technological companies with the proposed Digital Services Act package, the final shape and effects of which remain to be seen.

\section{The role of social media in shaping society}

The chapter by Aleš Rozehnal addresses social media's role in shaping society. The author indicates that most citizens, and therefore voters, use social media as their primary source of information and news. The Internet and social media thus shape our democratic dialog. Social media cannot stand above the law, but users should have the right to publish what they want, even if they risk consecutive sanctions by crossing the established limits.

In the Czech intellectual environment, the news presented by social media is what is recognized as the truth. If social media states that an event is true, it will be established as the truth regardless of the reality. The freedom of speech and the right to obtain information thus become imaginary because the only space for public discourse is in social media. Social media establishes the topics of discourse as well as the arguments and participants thereof. As opposed to autocratic censorship, democratic censorship is no longer based on omitting and deleting data but on the gathering, saturation, and surfeit of information. Thus, information is now distorted by volume.

The censorship today looks different and has different intentions in comparison with the past. It is based on more complex financial and commercial criteria, contrary to authoritative censorship. The flooding of information masks the lack of relevant information, and the images are often false and conceal the reality.

Everyone has the right to publish whatever they consider appropriate; this is the essence of freedom of speech. However, if they publish anything against the law, they must take responsibility for their actions. Freedom of speech is one of the basic pillars of a democratic society and one of the main conditions for self-development and self-fulfillment. This applies not only to information and opinions that are well-received and judged as non-aggressive or neutral but also to those that are aggressive, shocking, or irritating.

Freedom of speech and expression includes the free market of ideas in which false, criminal, and harmful doctrines will be overcome by true statements and right opinions. This freedom of the free market of ideas and the defeat of false ideas is beneficial to society as a whole. However, the issue is complex as freedom of speech has not only outer limits-limits by legal regulations-but also inner limits-immanent to this freedom. This is because freedom of speech also includes responsibility for the speech, which does not mean moral or philosophical responsibility but legal responsibility. 
Internet use has brought a new dimension to the expression of freedom of speech. The easy dissemination of information in cyberspace is such a change in the amount of information that it has resulted in a change in its quality and thus in the understanding of freedom of speech. Anyone can speak to numerous people with no physical or mental effort while receiving immediate responses. Moreover, this is fully or partially anonymous and contrary to the publication of articles in standard media that are highly elitist and extremely plebeian. At first sight, free and universal access to the Internet appears to have enabled as many people as possible to establish their own ideas in the social consciousness. For the first time in history, everyone has the same opportunity to accept others' and disseminate their own perspectives and thus participate in free civil society life. Thus, the Internet is a highly democratizing media environment that could strengthen human rights and civil liberties. Instead, we witness a mass of hate speech on the Internet, mainly surrounding discussions related to published issues, especially on news and journalistic servers. This hate speech is usually of such a characteristic that it interferes with the personal rights of other people in discussions or people discussed in the main issue, or it is so rude and vulgar that it violates the basic rules for civil coexistence. Such speech is often racist and xenophobic, proclaiming intolerance and contempt for democratic systems and other people's rights.

\section{The impact of digital platforms and social media on the freedom of expression and pluralism in Slovakia}

The chapter by Gábor Hulkó presents the regulation of social media platforms in connection to freedom of speech, content censorship, and "fake news" in Slovakia. The author highlights the relevance of social networks in Slovakia and discusses various aspects of the liability of media platforms and users. In general terms, two main questions arise concerning the state regulation of media platforms: one is the assessment of disputes and legal liability between users, and the other is the issue of the legal liability of platforms. In the Slovak legal system, users can sue each other in the usual way of the offline world, or they can conventionally accuse if they suspect that a crime has been committed. Legal procedures are the same in the online world. The regulation of the liability regime for content on social media platforms is a distinct matter, as it tampers with different questions: first, the responsibility of social media platforms for user-uploaded content; second, the reaction of social platforms to this uploaded content, such as banning users' posts and deleting (censoring) information. In this regard, social media platforms can influence the flow of information locally and globally; thus, they de facto intervene with individuals' freedom of expression and right to information. 
The freedom of expression and the right to information are guaranteed on a constitutional level in the general regulatory framework in Slovakia. Furthermore, censorship is prohibited on a constitutional basis. However, according to the prevailing doctrine, the concept of "censorship" is only relevant in cases in which the state faces the individual, meaning that censorship is only regarded as the actions of state organs. Therefore, this constitutional rule does not apply to the actions of private individuals or corporations capable of limiting, banning, or de facto censoring the views or opinions of others.

As pointed out in the chapter, social media platforms are not specifically regulated in the Slovak legal system, as subsidiaries rule the regulation for transposing the rules of the EU e-commerce Directive into national law can be applied. Regarding the liability of e-service providers and social media platforms, Slovakia follows Delfi AS v. Estonia's verdict.

The question of deleting user-uploaded information can be considered a bit of a gray area, as this type of information removal in stricto sensu does not qualify as an act of censorship. Only the interventions of the state are considered as censorship, but there is no actual legal definition for this term. Most authors define relevant conceptual features of censorship as its public power nature, meaning that the prohibition of censorship is addressed exclusively as the responsibility of the state. Interference with freedom of expression by private individuals-while not necessarily less threatening than interference by public authorities-cannot be considered as censorship under current Slovak regulations. However, some authors highlight that the concept of "censorship addressed exclusively to the state" is outdated and should be revised, as the forms of communication have changed and developed drastically. The system of public liability for content control by social media platforms is not known in the Slovak legal system with regard to alleged or actual censorship. The relationship between social media and the user is interpreted by Slovak law as a private law contract within the framework of which the user consents to the service provider to remove certain content. Therefore, if the information is deleted by the service provider, it can be challenged in court.

The concept of state intervention against fake news and similar types of disinformation is a current issue. It fully realizes that the important role of the state and its competent components is to create a mechanism to eliminate the impact of disinformation campaigns, especially through the effective identification of manipulative content and strategic communication. Therefore, a novel cybersecurity act and a governmental administrative action plan are prepared. The latter constitutes actions against disinformation as administrative tasks, for which most organs of the central state administration have tasks and obligations. 


\section{Freedom of expression on social networks: The international perspective}

The chapter by Dušan V. Popović discusses the issue of freedom of expression in relation to social media platforms from an international perspective. It discusses the legislation of the United States of America and the regulations of the Council of Europe and the EU.

The author points out that international and national legal documents do not use uniform terminology to designate the right to participate in public debates. The First Amendment of the United States Constitution, adopted in 1791, employs the term "freedom of speech." More recently adopted legal documents, however, employ the term "freedom of expression." For example, the Universal Declaration of Human Rights (UDHR) and the International Covenant on Civil and Political Rights (ICCPR), adopted in 1948 and 1966, respectively, state that individuals have the right to freedom of expression. This right includes the freedom to seek, receive, and impart information and ideas of all kinds. The European Convention on Human Rights also employs the term "freedom of expression." The concept of "freedom of speech" has been interpreted extensively to include not only direct speech (words) but also symbolic speech (actions). The Internet has undoubtedly introduced new forms of communication-new forms of expression of opinions. For example, a "like" on a social network is a form of speech, as it represents a statement made by an Internet user.

Since their inception, social networks such as Facebook and Twitter have been legally considered private spaces. However, in recent years, social networks have been increasingly perceived as forums of public communication. In line with this tendency, the US courts have examined whether public forum doctrine can be applied to social networks.

In recent years, concerns about the societal consequences of the online dissemination of disinformation and propaganda have become widespread. New digital tools that allow anyone to spread political information easily to numerous Internet users can lead to a more pluralistic public debate and also provide a platform for extremist voices and actors seeking to manipulate the political agenda for their political or financial interests. The problem of "fake news" attracted substantial attention during the 2016 US presidential elections. Given its complexity and the different ways in which it is perceived, the term "fake news" has been less employed in legal doctrine and legal documents in recent years than the term "disinformation." This is particularly the case in the EU within the context of recent European initiatives.

The self-regulatory approach to combating fake news, which is preferred by social networks, as well as the co-regulatory approach favored by the EU, typically faces several challenges. First, conflicts of interest may occur between the social networks' need to keep users engaged and monetize their engagement and public 
authorities' need to safeguard the integrity of democratic processes. Second, an enormous amount of content must be monitored, which necessarily implies the algorithmic screening of content and, consequently, the errors that could occur in that process. Third, the efficiency of fact-checking mechanisms is limited, as algorithms cannot be relied on for controlling the extreme amount of online content. Further, state-imposed direct regulation, preferred by certain European and nonEuropean countries, focuses on illegal content while ignoring many other variants of disinformation. 